\title{
Reframing the Debate on Asian Students and Critical Thinking: Implications for Western Universities
}

\author{
David Rear \\ Chuo University \\ daverear.175@g.chuo-u.ac.jp
}

\begin{abstract}
This paper examines the widespread contention that, as a result of their cultural and educational backgrounds, students from Asia lack the critical thinking skills required when they study abroad at Western universities. It scrutinises this view from two perspectives. First, it problematises the use of Asia as a monolithic entity, arguing that the stereotyping of Asian students as uncritical is an act of Othering that fails to recognise the cultural and social diversity of such a large group of people. Second, it looks at studies of the critical thinking skills of Asian students to determine whether there is empirical evidence that they do indeed lack these fundamental cognitive abilities. From a comprehensive review of the literature, it finds that most of the specific skills and dispositions included within the umbrella of critical thinking can be found in equal or greater measure in the traditions, cultures and education systems of many Asian countries. Much of the supposed paucity of critical thinking amongst international Asian students can be explained by the fact that they are carrying out their studies in a foreign language, which has been shown to have a significantly negative impact on academic performance.
\end{abstract}

\section{Introduction}

The internationalisation of higher education has given opportunities to a growing number of students to study at overseas universities. Many of the students taking such opportunities originate from Asia, with those from China forming the largest group, followed by India, Korea and Japan. In universities in Australia and New Zealand, for example, Asian students account for $80 \%$ and $69 \%$ respectively of the total international student population (OECD, 2009).

In such a context, it is natural that the specific needs of Asian students have come to be prominently discussed amongst Western educators. Central to this discussion has been the issue of critical thinking (CT) skills, the development of which has become an explicit goal of higher education institutions in the West. The contention has been that, as a result of their cultural and educational backgrounds, CT is particularly challenging for students from Asian nations (Ballard \& Clanchy, 1991; Ellwood, 2000; Davies, 2013, Shaheen, 2016). As Moore (2011) observes: the "simple binary of critical and non-critical educational cultures persists as a powerful image in our universities" (p. 12).

There is evidence that Asian students perform below the average in Western universities. In the UK, for example, while $69 \%$ of all students, and $52 \%$ of students from outside the EU, graduated with a first or 2.1 in 2013, this was true of only $42 \%$ of students from China (Swain, 2014). The question, however, is whether it is accurate to put this down to a lack of critical thinking ability rather than other factors, such as language skills. Critical thinking has become such an integral part of what universities

Journal of Contemporary Issues in Education, 2017, 12(2), pp. 18-33. ISSN 1718-4770 (C 2017 University of Alberta/Centre for Global Citizenship Education and Research http://ejournals.library.ualberta.ca/index.php/JCIE 
purport to both demand from their students and develop in their graduates that statements about certain cultures lacking these fundamental skills should not be made without careful consideration.

This paper provides a critical analysis of the contention that Asian students lack critical thinking. It argues that the discourse on Asian students is a form of Othering, in which differences between cultures, societies and individuals are rendered ambiguous or invisible. The 'large culture' approach of contrastive analysis masks not only the diversity of individuals but also the fluid, dynamic nature of social and cultural change through which stereotypes can easily become outdated or mistaken. The central assumptions of this discourse are questioned by an examination of three kinds of studies of direct relevance to the issue: (1) studies of cultural attitudes and dispositions towards critical thinking; (2) international comparisons of critical thinking and general academic performance; (3) the impact of language proficiency on academic success. It finds that, contrary to the accepted wisdom, there is little objective evidence to suggest Asian students are deficient in critical thinking in the broad sense of the term either in disposition or ability. It recommends, therefore, a reframing of the debate to more accurately reflect the realities of international education.

\section{What is Critical Thinking?}

In order to examine the argument that the cultures of Asia work against the kind of critical enquiry valued in Western education, we first need an idea of what critical thinking actually entails. While there are many specific definitions of the term, they tend to be broadly similar in substance. Angelo (1995) observes: "Most formal definitions characterize critical thinking as the intentional application of rational, higher order thinking skills, such as analysis, synthesis, problem recognition and problem solving, inference and evaluation" (p. 6). Halpern (1996), for example, says CT is "the kind of thinking involved in solving problems, formulating inferences, calculating likelihoods, and making decisions" (p. 117). Critical thinking has also been broken down into taxonomies of skills that attempt to define it in a more detailed form (Bloom, 1956; Ennis, 1987; Facione, 1990; Anderson \& Krathwohl, 2001). Facione (1990), for example, lists six broad categories of interpretation, analysis, evaluation, inference, explanation, and self-regulation, which include within them sub-skills such as categorisation, clarifying meaning, examining ideas, analysing arguments, assessing claims, drawing conclusions, stating results, justifying procedures, presenting arguments, self-examination and self-correction.

Typically, definitions of CT also include lists of dispositions that govern the willingness of the user to employ thinking skills in their everyday lives. Beyer (1985) argues that CT requires a 'frame of mind' as well as specific mental operations. This frame of mind includes an alertness to the need to evaluate information, a willingness to test opinions, and a desire to consider all viewpoints. Paul and Nosich (1991) believe that "critical thinking entails the possession and active use of a set of traits of mind, including independence of thought, fairmindedness, intellectual humility, intellectual courage, intellectual perseverance, intellectual integrity, curiosity, confidence in reason, the willingness to see objections, to enter sympathetically into another's point of view" (p. 5).

Several significant points emerge from the above definitions. First is the broad span of skills and dispositions that are included within the umbrella of critical thinking. They include not only skills of argumentation, such as synthesis and evaluation, but also those of problem identification and problem solving. This takes CT beyond the confines of essay writing and debate and into contexts such as

Journal of Contemporary Issues in Education, 2017, 12(2), pp. 18-33. ISSN 1718-4770 @ 2017 University of Alberta/Centre for Global Citizenship Education and Research http://ejournals.library.ualberta.ca/index.php/JCIE 
business, engineering, science and technology. Almost all definitions of CT place an emphasis on drawing conclusions on the basis of careful, objective analysis of evidence, which as Paton (2005) has pointed out, explicitly links the concept with the scientific method. Scott and Markert (1994) note that "generally, it is held that medical education trains students to use critical thinking skills in active problem solving regarding patient care" (p. 920). In the engineering field, Siller (2001) argues that the “development of students' abilities to think critically about engineering problems and design projects is an important educational objective" (p. 108). If it is true, therefore, that Asians are generally deficient in critical thinking, it follows that they should also be less successful in scientific disciplines which utilise the same set of cognitive skills.

A second point concerns the relationship between critical thinking and general intelligence. Most theorists regard CT as an approach or attitude, suggesting that people have a choice about whether or not to apply it in their everyday lives. This separates the concept from pure brainpower. Nevertheless, there is an obvious link between CT and intellectual ability, as a number of researchers have pointed out (Nickerson, Perkins \& Smith, 1985; Halpern, 2007). The conduct of research, the collection and analysis of data, the formulation of convincing arguments, the logical explanation of conclusions, the solving of complex problems: such tasks require intellectual competence in order to be performed to a high level. Interestingly, in a large-scale international comparison of academic ability conducted by the OECD (to be introduced in more detail below), there was a strong correlation between test scores in problem solving and scores in maths, science and reading, indicating that general academic ability is a powerful predictor of other cognitive skills.

A final point to make is that, while CT is of clear relevance to argument, it says nothing about the style in which these arguments are made. We often associate CT with the cut-and-thrust style of academic debate, but most conceptions of the term also emphasise the more empathetic qualities of openmindedness and dialogical/dialectical thinking. Facione (1990), for example, includes 'open-mindedness regarding divergent world views', 'understanding of the opinions of other people', and 'fair-mindedness in appraising reasoning' within his list of dispositions. Thayer-Bacon (1993) has argued that the dimension of 'care' needs to be explicitly added to conceptions of CT. Caring about other people, she says, is vital if we are to reach a fair and empathetic understanding of their views. The emphasis that critical thinking places on scepticism brings with it the danger that we will rush to push forward counterarguments before fully considering the worth of opposing opinions. Critical thinking can, on the contrary, be practised in a collaborative manner, with group rather than individual decision-making as its final product, a point that is of relevance when we consider ideas about Asian cultural values and their impact on $\mathrm{CT}$.

\section{The Discourse of Asian Students and Critical Thinking}

The starting-point of this paper is the oft-made assertion that students from Asia lack the critical thinking skills demanded by universities in the West (Ballard \& Clanchy, 1991; Ellwood, 2000; Lee \& Carrasquillo, 2006; Davies, 2013). As Paton (2005) has observed: "In an oft-heard expression of exasperation, academics in Australia claim that Chinese students do not partake naturally in critical thinking because of a perception of mere rote learning and the lack of overt participation in classroom discussions" (p. 1). Japanese students taking an ethnographic culture course at the University of

Journal of Contemporary Issues in Education, 2017, 12(2), pp. 18-33. ISSN 1718-4770 @ 2017 University of Alberta/Centre for Global Citizenship Education and Research http://ejournals.library.ualberta.ca/index.php/JCIE 
Technology in Sydney, for example, were said to "fit the stereotypes of being passive and nonparticipatory, with little ability in the type of critical enquiry which is so valued by the western academy" (Ellwood, 2000, p. 4).

With Asian students forming a significant majority of the international student population, any discourse that passes judgement on their academic abilities must be interrogated thoroughly. Discourse does not simply mirror an objective reality; it possesses an ontological 'hardness' (Watson, 2000) that actively contributes to the creation and transformation of social identities, relationships and knowledge structures (Foucault, 1972; Fairclough, 1992). If Asian students are articulated widely as lacking fundamental skills possessed by their Western counterparts, this has the potential to form a significant aspect of their identities as students, affecting not only their evaluation, performance and relationships at university but also beyond that in their employment prospects or further education paths.

When the discourse of Asian students is examined critically, it bears the hallmarks of Othering, which can be defined as "the ways in which the discourse of a particular group defines other groups in opposition to itself; an Us and Them view that constructs an identity for the Other and, implicitly, for the Self' (Palfreyman, 2005, p. 216). In the process of Othering, differences within one particular group tend to be downplayed while differences between groups are overstated, leading to a reliance on stereotypes, often negative, that oversimplify cultural attributes. Such a binary approach to the study of culture, even when well-meaning, has been heavily criticised by a number of researchers (Biggs, 1996; Kubota, 2001; Guest, 2002; Doherty \& Singh, 2007). Guest (2002), for example, lists several potentially adverse effects of contrastive analysis:

1. It may serve to ignore the richness and diversity within a culture, reducing it to a caricature lacking real understanding or analysis. Sub-cultures are overlooked, as are differences between men and women, old and young and so on. Likewise, when dealing with a regional block, such as Asia, variations between national cultures are also ignored.

2. It reduces cultural understanding to discrete declarative propositions ('essences') which serve as 'interpretative pegs' for all social behaviour or attitudes. Instead of viewing learners as individuals with their own personalities, strengths and weaknesses, as we would do with students from our own culture, we reduce them to a single monolithic group, interpreting their behaviour through a cultural lens.

3. It tends to undermine the fact that cultural attributes exist along a continuum rather than discrete either/or categories, leading to over-generalisations such as 'Westerners are individualistic and Asians are group-oriented'. Reality is messier and more complex than such categories allow for.

4. It portrays cultures as not only homogeneous but also static and unchanging. In the twenty-first century, cultural boundaries and identities are becoming increasingly blurred and intermingled under the influence of globalisation. This is particularly true of families who encourage their children to study overseas, with all the expense and difficulty that involves. The Asia of today is not the same as the Asia of twenty or thirty years ago, no matter how 'sticky' cultural values are said to be.

5. Contrastive analysis is a method regularly employed by nationalists, racists and other extremists to support exclusionary agendas. By encouraging the fossilisation of stereotypes, the contrastive approach may serve to exacerbate antagonism rather than understanding or mutual respect.

While educators who have criticised Asian learners are employing contrastive analysis as a method to explain behaviour they observe in the classroom rather than to support a deliberately 
exclusionary agenda, many of the points listed above can be identified within their arguments, which attribute supposed deficiences in critical thinking to purely cultural factors. In this discourse, critical thinking is portrayed as a uniquely Western construct that developed out of the Socratic method of questioning knowledge claims (Lloyd, 1996; Tweed \& Lehman, 2002; Egege \& Kutieleh, 2004). Egege and Kutieleh (2004) describe the use of "analysis, logic, argument structure and the scientific method" as "very much a Western cultural product" (p. 80), while Atkinson (1997) argues that critical thinking is a social practice learned "through the pores" (p. 73) through long inculcation into Western cultural norms. By contrast, Asian cultures are said to be based on the Confucian principle of deference toward authority, which acts to discourage the kind of critical questioning valued in the West (Ballard \& Clanchy, 1991; Biggs, 1996; Cadman, 2000). Ballard and Clanchy (1991) quote Confucius as saying, "I do not invent, but transmit", and extrapolate from this an overarching cultural attitude in Asia toward "conserving" rather than "extending" knowledge. Ballard (1987) suggests:

In Western education it is axiomatic that knowledge is gained and extended through critical analysis, by individuals working with increasing independence... yet such a view, we often forget, is culture-bound. In Asia, for example, knowledge if not open to challenge and extension in this way, and academic education may have little to do with the beginning of wisdom (p. 114).

These cultural attitudes are said to be reflected in educational practices. Learning environments in countries such as China, Japan, Korea and Singapore tend to be characterised by large class sizes, authoritarian teaching, rote memorisation and exam-driven learning, which researchers have linked with so-called 'surface learning' in contrast to the 'deep learning' approach promoted by the more interactive environments of Western classrooms (Watkins \& Biggs, 2001; Lun, 2010). Consequently, when students raised in these authoritarian educational cultures encounter the freer environments of Western universities, they show either an inability or an unwillingness to participate in class discussions. Gieve (1998) argues, therefore, that inculcating Asian students into Western classrooms "may require a wholesale reorientation of students' cultural norms, values, beliefs, and attitudes" (p. 128).

From the oversimplification of the teachings of Confucius and the assumption that they still form the basis of all Asian cultures to the critique of Asian education as oriented to surface rather than deep learning, these statements exemplify the Othering process outlined above. As Moore (2011) has observed, the "simple binary of critical and non-critical educational cultures persists as a powerful image in our universities" (p. 12). This has several potential effects on Asian learners and their experience at Western institutions.

Arguably the most deleterious effect is that Asian students are seen as having significant deficiences in their academic abilities compared to their Western classmates. While the image of large class sizes and teacher-centred modes of learning may have a basis in fact (though surely not for all schools in all of Asia), does this automatically mean that Asian students are incapable of critical thought? Until relatively recently, the cultures of education systems in the West were not so different. Are the parents and grandparents of Western students similarly hamstrung in their critical abilities? These details are missing from a debate based on contrastive analysis. Likewise, it ignores the fact that many Western students also arrive at university unprepared for this new kind of learning environment. Several studies have found that students make gradual adjustments to their belief systems about knowledge and learning

Journal of Contemporary Issues in Education, 2017, 12(2), pp. 18-33. 
during their time at higher education (Perry, 1988; Durkin, 2008). Western students, of course, have the advantage of doing so in their first rather than second language.

In the 'deficit' approach to international education, the attributes of overseas students are seen as requiring pedagogic intervention and correction from Western teachers, commonly in one-year 'Foundation' programs before entrance into undergraduate courses. Such programs focus not only on English competence, but also on cultural training and academic skills, which the students are assumed to be lacking (Doherty \& Singh, 2007). Local students, on the other hand, are permitted to pass straight into their undergraduate studies, under the assumption that their academic skills are already sufficient.

The Othering of Asian students also has a potential effect on their social lives by separating them discursively from their Western counterparts. Since for most international students the primary reason for investing in a Western education is the development of native-like fluency in English, a lack of interaction with domestic students can be a source of significant frustration (Doherty \& Singh, 2007). A national survey of international students carried out in New Zealand, for example, reported that low levels of contact between international and domestic students was noted mostly by Asian students and was a cause of significant concern among them (Ward \& Masgoret, 2004). Linking this unfortunate trend directly to discourse, Collins (2006) has described how media representations of Asian students in Auckland, in which they were fixed within a single racial identity known by stereotypical economic, cultural and social characteristics, has problematised interaction between international students and the local population.

The discourse of Asian learners as uncritical and passive has become widespread in Western universities, passing almost unchallenged as an educational orthodoxy. In the next section, this representation will be critiqued through an examination of empirical studies that have compared the learning dispositions of Asian and Western students.

\section{Critical Thinking and Asian Cultures}

It is hard to deny that cultural background plays a role in how students behave within the classroom. Anyone who has taught ESL classes to students of different nationalities has observed differences in the way students interact with each other and the teacher. A room full of Italian students will not sound like a room full of Japanese. A class of Asian students is likely to be quieter, with longer silences, fewer questions and less active discussion. Learners tend to communicate with each other and their teacher in a more indirect fashion, generally shying away from putting themselves forward too actively or contradicting each other too vocally (Holmes, 2008).

It would be hazardous, however, to equate a quiet classroom with a deficiency in cognitive skills or a disinterest in the learning material. Quite the opposite may well be true. Many studies have shown that, in contrast to their Western counterparts, Asian students perceive silence to be an important component of deep thinking (Harklau, 1994; Kim, 2002). Chiu (2008), for example, has identified three types of silence observed among Asian students, only one of which is indicative of an absence of ideas. We must also bear in mind that critical thinking does not need to take place in an atmosphere of heated discussion and debate. A study by Durkin (2008), for example, showed that Asian students are able to adapt to the norms of critical debate and argumentation while retaining values that preserve social harmony and face.

Journal of Contemporary Issues in Education, 2017, 12(2), pp. 18-33. ISSN 1718-4770 (C 2017 University of Alberta/Centre for Global Citizenship Education and Research http://ejournals.library.ualberta.ca/index.php/JCIE 
On a more general level, while Asian education may encourage a respectful attitude towards teachers in the classroom, it is easy to exaggerate the extent to which Asian people evince deference towards authority in their societies as a whole. One only needs to consider the anti-government protests that take place regularly across the region or the lively political debates featured in print or television media to see the fallacy of this point of view. Many protests are, in fact, led by young people, notably the pro-democracy activists in Hong Kong and even the SEALDs (Students Emergency Action for Liberal Democracy) group in Japan.

In terms of education, scholars have also cast doubt on the theory that Confucianism encourages a passive approach to knowledge and learning. Kim (2003) has pointed out that, rather than simply asking his followers to blindly accept what they were told by authorities, Confucius encouraged two kinds of reflective thinking: reflection on materials of knowledge to synthesise, systemise and integrate the raw materials into a whole; and reflection on oneself to ensure that such synthesis, systemisations and integration proceed in an open-minded, fair and autonomous way. Such principles sound remarkably similar to modern conceptions of critical thinking. Paton (2005), meanwhile, has taken issue with the argument that scientific thinking is a peculiarly Western construct, showing that various forms of scientific thinking have been a major aspect of Chinese culture for over a thousand years. In research on cognitive psychology, although Asians and Westerners have been found to possess a few differences in their cognitive styles and modes of reasoning, these have not linked to a negative impact on critical thinking (Nisbett et al., 2001).

There is also little evidence that Asian students have fundamentally different dispositions when it comes to learning and the use of critical thinking. While some studies carried out by Chinese scholars have found that Chinese do not have positive dispositions towards critical thinking, other studies have discovered the opposite (see Tian \& Low, 2011). In comparisons between Asian and Western learners, most researchers have found few if any differences between them. Manalo et al. (2013) examined the concept of 'independent and interdependent self-construals', theorising that the psychological need among students in Japan to 'fit in with relevant others' might lead to differences in how critical thinking was perceived. In fact, however, when compared to students in New Zealand, the researchers found "no differences ... between the groups on reported critical thinking use" (p. 121). Other studies by McBride et al. (2002), Tiwari et al. (2003) and Jones (2005) also found similar views on critical thinking between Western and Chinese students, with Westerners displaying comparable concerns about maintaining personal harmony with their peers. Finally, in interviews with Chinese students about their learning, Paton (2011) and O'Sullivan and Guo (2010) discovered that they had clear and positive ideas about critical thinking, displaying a strong sense of individuality and a rejection of conformism and rote learning. Paton (2011) concluded that 'the depth and variety of thought shown in the students' responses indicate a remarkable level of critical thinking, which would seem to belie the strident claims by those such as Atkinson (1997) that critical thinking is the preserve of Western culture" (p. 36).

Some of the similarity that has been observed between Western and Asian learners in CT dispositions may be due to changes that have taken place within countries such as China, Korea and Japan over the past ten to fifteen years. With so many Asian students now choosing to study abroad, it is almost inevitable that concepts like critical thinking will have seeped into the domestic educational discourse, even if this does not necessarily lead to direct changes in educational practice. In Japan, universities have certainly taken on board the importance of developing students' thinking and problem solving skills, both

Journal of Contemporary Issues in Education, 2017, 12(2), pp. 18-33. 
as a discourse and in practical terms. While the term 'critical thinking' itself is used only seldomly, the mission statements of most universities revolve around learning objectives of a similar character. The largest university in Japan, Nihon University, for example, challenges its students to "discover problems by yourself, to gather, analyse and sort through necessary information, and, by enlisting the help of those around you, to find solutions" (Nihon University, homepage).

\section{International Comparisons of CT and Academic Performance}

Despite the widespread view that Asian students lack critical thinking, there has, in fact, been very little research directly comparing the CT skills (as opposed to dispositions) of students of different nationalities. In a review of the literature on Chinese students and critical thinking, Tian and Low (2011) were able to find no empirical studies that tested the CT abilities of Mainland Chinese students. In 2016, however, a study conducted by researchers at Stanford University (to be published in 2017) found that Chinese freshmen in computer science and engineering programmes began college with critical thinking skills, including the ability to identify assumptions, test hypotheses and draw relationships between variables, around two or three years ahead of their peers in the United States and Russia (Hernandez, 2016). (Interestingly, the study also found that the CT skills of the students stagnated while at university in China.) Another study conducted by Hau et al. (2006) reported that Chinese students in Hong Kong scored significantly higher than American university students on the Halpern Critical Thinking Assessment using Everyday Situations, though they surmised this may have been due to the Chinese sample being recruited from a more selective institution than the American sample.

A more well-publicised set of data comes from the OECD's Programme for International Student Assessment (PISA). In the PISA tests, Asian countries have been found to significantly outperform their Western counterparts, a phenomenon that is sometimes referred to as the 'Asian paradox'. In 2014, for instance, students from Asian countries not only occupied the top seven places in mathematics (headed by China and Singapore), the top five places in reading and the top four places in science, they also scored significantly higher in a newly-developed problem solving test, with students from Singapore and Korea at the top followed by Japan and China. The problem solving test, conducted in 2012 for the first time, tests pupils' ability to devise strategies for tackling unfamiliar problems in a variety of contexts, from working out the quickest travel time across a city to dealing with a new digital device. Those pupils who excelled in the test were described by the OECD as "quick learners, highly inquisitive and able to solve unstructured problems in unfamiliar contexts" (OECD, 2014, p. 44). The Financial Times, in a report entitled 'Countries that excel at problem-solving encourage critical thinking', stated that "critics of Asian education systems attribute their success in maths and science to rote learning.... But the OECD's assessment suggests that schools in east Asia are developing thinking skills as well as providing a solid grounding in core subjects" (Vasagar, 2014).

How can we explain the strong performance of Asian students in such a diverse selection of tests? One possible reason is the high regard in which teaching as a profession is held in Asia, the relatively low scale of disciplinary problems within the classroom and the longer hours pupils spend in school on the whole, which together may permit more learning to take place. A second possible explanation is that Asian learning environments are not as exam-driven and authoritarian as the stereotype suggests. In Japan, teenagers performed significantly better in problem solving than in the other three 
academic tests. The OECD suggested this might be explained by Japan's focus on developing problem solving skills through cross-curricular, student-led projects. Observations of maths lessons in both Japan and China have revealed that, unlike in many Western classrooms, teachers encourage pupils to analyse maths problems in an inductive and intuitive manner (Stigler et al., 1998), fostering deeper understanding of the methods involved. There is also the possibility that rote memorisation itself does not necessarily lead to only a superficial understanding of the learning material. Kember (1996) argues, for example, that Asian students employ a combination of both surface and deep learning approaches as they process what they have memorised in order to achieve greater understanding.

\section{The Impact of Language Proficiency on Critical Thinking}

With little evidence backing up the assertion that Asian students are inferior in critical thinking or that they lack the dispositions to apply it in their studies, we are left with the conundrum posed by the problems they seem to face in adapting to the academic expectations of Western universities. In this context, however, we are hit with the very obvious factor of language. While language is often mentioned as a contributing factor to the struggles faced by Asian students, there is a tendency to either underestimate its impact or conflate it with the issue of critical thinking. Davies (2013), for example, writes of the difficulties in assimilating "the large numbers of international students in universities who struggle with English and who come from cultures unused to the critical, argumentative culture of western universities" (p. 14).

Anyone who has had to carry out high-level communicative functions in a second or third language will be aware of the significant challenges of doing so. It is not only more difficult to find the correct words to say but also to spot logical weaknesses in the spoken or written arguments of others. There is a term for this phenomenon: 'cognitive overload'. According to cognitive overload theory, the amount of information that can be stored and processed in the working memory is limited (Paas et al., 2003). For ESL students, the act of processing unfamiliar language structures has been shown to use up some of that limited working memory, negatively impacting their performance on cognitive tasks, including on relatively non-linguistic tasks such as maths problems (Cook, 1993; Kirby et al., 1996; Koda, 2005; Campbell et al., 2007).

There is no shortage of evidence linking language proficiency with critical thinking. For native speakers of English, Taube (1997) and Clifford et al. (2004) found that verbal comprehension scores in SATs and similar tests correlated positively with results in CT tests. Grosser and Nel (2013) tested the CT skills of South African trainee teachers and found "significant correlations between academic language proficiency and making inferences, as well as between academic language proficiency and critical thinking as a general competency" (Grosser \& Nel, 2013, p. 1).

In terms of L1 versus L2 performance in academic tasks, the results are similarly clear-cut. Takano and Noda (1993) observed that speakers of Japanese performed less well on a calculation task when they carried it out in English rather than in Japanese, while native speakers of English did less well when doing the task in Japanese. Manalo and Uesaka (2012) found that a lower proficiency in L2 limited the ability of students to use diagrams when explaining information in that language. Clerehan (1995) compared the note-taking skills of L1 and L2 students in Australia and found that the L2 students' notes were much less comprehensive than those of the L1 students. She attributed this to their language 
proficiency, stating that L2 students are at a "huge disadvantage" (Clerehan, 1995, p. 145). Finally, for essay writing, L2 writers have been found to be significantly impaired due to the strain that L2 places on lexical expression, syntax, cohesion, strategy use and ease of writing (Basturkmen \& Lewis, 2002; Myles, 2002).

In terms of CT itself, Floyd (2011) tested Chinese speakers with the Watson Glaser Critical Thinking Appraisal and observed that scores were significantly higher when they did the test in their native language than in English. More evidence of the detrimental effects of L2 on CT was found by Manalo, Watanabe and Sheppard (2013) with tests on Japanese students and Lun et al. (2010) with tests on Chinese students. Lun et al. (2010) concluded that: "Asian students' apparent lack of critical thinking is a consequence of the need to use English as a second language in academic discourse. Without sufficient English proficiency and/or enough confidence in using the language, Asian students are discouraged from overtly expressing their critical thinking in classrooms even if they want to do so" (p. 614).

Students from China, Japan or Korea face the additional burden of their first language being so linguistically different from English. Significantly, the Foreign Service Institute of the US State Department ranks Mandarin, Cantonese, Japanese and Korean as the most difficult languages for English speakers to learn, suggesting the reverse is likely to be true also. This helps to explain why east Asian students tend to struggle more than international students from other nations.

\section{Discussion and Implications}

So, where does the evidence presented above leave us? It is true that the environments of Western universities seem to pose problems for Asian students, who perform less well on average in comparison to both domestic and other international students. But to what extent can we attribute this to either a lack of critical thinking ability or an unwillingness to apply it in their studies? Skills commonly included within the umbrella of CT include analytical ability, reasoning, logical thinking, inferencing, deduction, objectivity, scientific thinking, problem solving and self-reflection. To assert that an entire continent of learners lack all of these skills, or the disposition to apply them, is not a statement that should be allowed to pass unchallenged. The discourse of Asian learners possesses the hallmarks of Othering, in which the cultural attributes of one group are represented as a static and monolithic contrast to the Us of one's own group. For Asian students at Western universities, this can have real-life effects on their learning, evaluation and social interactions.

Assumptions about learners should not be made without evidence from empirical studies. Having reviewed dozens of such studies, it is hard to support the conclusion that cultural factors inhibit the use of critical thinking skills by Asian students. In terms of skills and dispositions, they appear to take a similar approach to their learning as students in the West do. In fact, in many tests of critical thinking they have been found to outperform their Western counterparts by a significant margin. The complaints made by Western academics about Asian students are concerned with a very specific issue: the formulation of arguments in essay writing and / or academic discussion. There is indeed evidence that Asian students gain less practice at these tasks in school than their counterparts in the West due to the focus on factbased examinations (Shaheen, 2016; Mulvey, 2016). That said, however, essay writing is not entirely absent from education in Asia. The ultra-competitive gaokao university entrance exams in China require

Journal of Contemporary Issues in Education, 2017, 12(2), pp. 18-33. ISSN 1718-4770 (C) 2017 University of Alberta/Centre for Global Citizenship Education and Research http://ejournals.library.ualberta.ca/index.php/JCIE 
students to produce essays on philosophical, moral or civic issues, while the exams of some high-level colleges in Japan also require extended pieces of argumentative writing.

More critical than a lack of experience is the overwhelming disadvantage that comes from having to carry out these tasks in a foreign language. When we break down the steps required to write an academic essay, they are loaded with sophisticated linguistic demands: understanding and summarising complex academic texts; synthesising those texts into a coherent argument; expressing that argument in the discursive style of a particular academic discipline. Successful argumentation also requires extensive knowledge of the subject matter, knowledge that is much harder to assimilate when being presented and processed in a foreign language. As previous studies have shown, Western students too must make adjustments to their beliefs about learning and knowledge as they enter higher education (Perry, 1988; Durkin, 2008). It is not surprising that the additional burden of a foreign language should make this process of development more challenging for students from overseas.

So, what lessons can we draw from this analysis? First and foremost, we should be careful about stating that Asian students lack critical thinking skills, a term too vague to be of value in this context. The evidence overwhelmingly suggests that Asian students do know how to think and they are willing to engage critically and creatively with academic content, whether it is in the humanities or the sciences. Research shows that it is the issue of language proficiency that needs to be most urgently tackled, in terms of both the standards required of international students to enter university and the foundation courses they take upon admission. It is unhelpful and potentially misleading to focus on cultural factors in such courses, since this may serve to exacerbate divisions between international and domestic students rather than diminish them. To say that Asian students need help with English essay writing when they enter college gives the issue a definable and verifiable focus; saying they lack the capacity for critical thought does not.

\section{References}

Anderson, L., \& Krathwohl, D. (2001). A taxonomy for learning, teaching and assessing: A revision of Bloom's taxonomy of educational objectives. New York: Longman.

Angelo, T. (1995). Beginning the dialogue: Thoughts on promoting critical thinking: Classroom assessment for critical thinking. Teaching of Psychology, 22(1), 6-7. https://doi.org/10.1207/s15328023top2201_1

Atkinson, D. (1997). A critical approach to critical thinking in TESOL. TESOL Quarterly, 31(1), 71-94. https://doi.org/10.2307/3587975

Ballard, B. (1987). Academic adjustment: the other side of the export dollar. Higher Education Research and Development, 6(2), 109-119. https://doi.org/10.1080/0729436870060203

Ballard, B., \& Clanchy, J. (1991). Teaching students from overseas: A brief guide for lecturers and supervisors. Melbourne: Longman Cheshire.

Basturkmen, H., \& Lewis, M. (2002). Learner perspectives of success in an EAP writing course. Assessing Writing, 8, 31-46. https://doi.org/10.1016/s1075-2935(02)00032-6

Beyer, B. (1985). Critical thinking: What is it? Social Education, 49, 270-276.

Biggs, J. (1996). Western misconception of the Confucian-heritage learning culture. In D. Watkins \& J. Biggs (Eds.), The Chinese learner: Culture, psychological, and contextual influences (pp.45-67).

Journal of Contemporary Issues in Education, 2017, 12(2), pp. 18-33. 
Hong Kong: Comparative Education Research Centre \& The Australian Council for Educational Research.

Bloom, B. S. (1956). Taxonomy of educational objectives. New York: D. McKay Co.

Cadman, K. (2000). Voices in the air: Evaluations of the learning experiences of international postgraduates and their supervisors. Teaching in Higher Education, 5(4), 475-491. https://doi.org/10.1080/713699170

Campbell, A., Adams, V., \& Davis, G. (2007). Cognitive demands and second-language learners: A framework for analyzing mathematics instructional contexts. Mathematical Thinking and Learning, 9(1), 3-30. https://doi.org/10.1080/10986060709336603

Chiu, Y. C. J. (2008). Technical and pedagogical support for EFL online interactions. Journal of Foreign Language Instruction, 2(1), 83-102.

Clerehan, R. (1995). Taking it down: Notetaking practices of L1 and L2 students. English for Specific Purposes, 14, 137-155. https://doi.org/10.1016/0889-4906(95)00003-a

Clifford, J., Boufal, M., \& Kurtz, J. (2004). Personality traits and critical thinking skills in college students: Empirical tests of a two-factor theory. Assessment, 11(2), 169-176. https://doi.org/10.1177/1073191104263250

Collins, F. (2006). Making Asian students, making students Asian: The racialisation of export education in Auckland, New Zealand. Asia Pacific Viewpoint, 47(2), 217-234. https://doi.org/10.1111/j.1467-8373.2006.00308.x

Cook, V. (1993). Linguistics and second language acquisition. London: Macmillan. https://doi.org/10.1007/978-1-349-22853-9

Davies, M. (2013). Critical thinking and the disciplines reconsidered. Higher Education Research \& Development, 32, 529-544. https://doi.org/10.1080/07294360.2012.697878

Doherty, C., \& Singh, P. (2007). Mobile students, flexible identities and liquid modernity: Disrupting Western teachers' assumptions of 'the Asian learner'. In D. Palfreyman \& D. McBride (Eds.), Learning and teaching across cultures in higher education (pp. 114-132). London, New York: Palgrave Macmillan. https://doi.org/10.1057/9780230590427_7

Durkin, K. (2008). The middle way: East Asian masters' students' perceptions of critical argumentation in U.K. universities. Journal of Studies in International Education, 12(1), 38-55. https://doi.org/10.1177/1028315307302839

Egege, S., \& Kutieleh, S. (2004). Critical thinking: Teaching foreign notions to foreign students. International Education Journal, 4(4), 75-85.

Ellwood, C. (2000). Dissolving and resolving cultural expectations: Socio-cultural approaches to program development for international students, presented at the National Language and Academic Skills Conference, La Trobe University, Melbourne, 2000.

Ennis, R. (1987). A taxonomy of critical thinking dispositions and abilities. In J. Baron \& R.J. Sternberg (Eds.), Teaching thinking skills: Theory and practice (pp. 9-26). New York, NY: W. H. Freeman and Company.

Facione, P. (1990). Critical thinking: A statement of expert consensus - The Delphi Report. California: California Academic Press.

Fairclough, N. (1992). Discourse and social change. Cambridge, UK: Polity Press. https://doi.org/10.2307/2074659

Journal of Contemporary Issues in Education, 2017, 12(2), pp. 18-33. ISSN 1718-4770 @ 2017 University of Alberta/Centre for Global Citizenship Education and Research http://ejournals.library.ualberta.ca/index.php/JCIE 
Floyd, C. (2011). Critical thinking in a second language. Higher Education Research and Development, 30, 289-302. https://doi.org/10.1080/07294360.2010.501076

Foucault, M. (1972). Archeology of knowledge. New York: Pantheon.

Gieve, S. (1998). Comments on Dwight Atkinson's ‘A critical approach to critical thinking in TESOL. TESOL Quarterly, 32(1), 123-129. https://doi.org/10.2307/3587907

Grosser, M., \& Nel, M. (2013). The relationship between the critical thinking skills and the academic language proficiency of prospective teachers. South African Journal of Education, 33(2), 1-17. https://doi.org/10.15700/saje.v33n2a639

Guest, M. (2002). A critical 'checkbook' for culture teaching and learning. ELT Journal, 56(2), 154-161. https://doi.org/10.1093/elt/56.2.154

Halpern, D. (1996). Thought and knowledge: An introduction to critical thinking (3rd ed.). Mahwah, NJ: Erlbaum.

Halpern, D. (2007). The nature and nurture of critical thinking. In R.J. Sternberg, H. Roediger \& D. Halpern (Eds.), Critical thinking in psychology (pp.1-14). New York: Cambridge University Press. https://doi.org/10.1017/cbo9780511804632.002

Harklau, L. (1994). ESL versus mainstream classes: Contrasting L2 learning environments. TESOL Quarterly, 28, 241-272. https://doi.org/10.2307/3587433

Hau, K. T., Halpern, D., Marin-Burkhart, L., Ho, I. T., Ku, K. Y. L., \& Chan, N. M. (2006). Chinese and United States Students' critical thinking: Cross-cultural validation of a critical thinking assessment. Paper presented at American Educational Research Association Annual Meeting, San Francisco, 2006. Retrieved from http://commons.ln.edu.hk/sw_master/3348/

Hernandez, J. (2016). Study finds Chinese students excel at critical thinking. Until college. New York Times, 30 July. Retrieved from https://www.nytimes.com/2016/07/31/world/asia/china-collegeeducation-quality.html?mcubz=3

Holmes, P. (2008). Foregrounding harmony: Chinese international students' voices in communication with their New Zealand peers. China Media Research, 4(4), 102-110.

Jones, A. (2005). Culture and context: Critical thinking and student learning in introductory macroeconomics. Studies in Higher Education, 30(3), 339-354. https://doi.org/10.1080/03075070500095788

Kember, D. (1996). The intention to both memorise and understand: Another approach to learning? Higher Education, 31, 341-354. https://doi.org/10.1007/bf00128436

Kim, H. S. (2002). We talk, therefore we think? A cultural analysis of the effect of talking on thinking. Journal of Personality and Social Psychology, 83, 828-842. https://doi.org/10.1037//00223514.83.4.828

Kim, H. K. (2003). Critical thinking, learning, and Confucius: A positive assessment. Journal of Philosophy of Education, 37(1), 71-87. https://doi.org/10.1111/1467-9752.3701005

Kirby, J., Woodhouse, R., \& Ma, Y. (1996). Studying in a second language: The experiences of Chinese students in Canada. In D. A. Watkins \& J. B. Biggs (Eds.), The Chinese learner: Cultural, psychological and contextual influences (pp.141-158). Hong Kong and Melbourne: Comparative Educational Research Centre and Australian Council for Educational Research.

Koda, K. (2005). Insights into second language reading. Cambridge: Cambridge University Press. https://doi.org/10.1017/cbo9781139524841

Journal of Contemporary Issues in Education, 2017, 12(2), pp. 18-33.

ISSN 1718-4770 @ 2017 University of Alberta/Centre for Global Citizenship Education and Research http://ejournals.library.ualberta.ca/index.php/JCIE 
Kubota, R. (2001). Discursive construction of the images of U.S. classrooms. TESOL Quarterly, 35(1), 938. https://doi.org/10.2307/3587858

Lee, K. S., \& Carrasquillo, A. (2006). Korean college students in United States: Perceptions of professors and students. College Student Journal, 40(2), 442-456.

Lloyd, G. (1996). Adversaries and authorities: Investigations into ancient Greek and Chinese science. Cambridge: Cambridge University Press.

Lun, V. (2010). Examining the influence of culture on critical thinking in higher education. Doctoral dissertation. Wellington: Victoria University of Wellington. Retrieved from http:/hdl.handle.net/10063/1211

Lun, V., Fischer, R., \& Ward, C. (2010). Exploring cultural differences in critical thinking: Is it about my thinking style or is it the language I speak? Learning and Individual Differences, 20, 604-616. https://doi.org/10.1016/j.lindif.2010.07.001

Manalo, E., Kusumi, T., Koyasu, M., Michita, Y., \& Tanaka, Y. (2013). To what extent do culture-related factors influence university students' critical thinking use? Thinking Skills and Creativity, 10, 121-132. https://doi.org/10.1016/j.tsc.2013.08.003

Manalo, E., Watanabe, K., \& Sheppard, C. (2013). Do language structure or language proficiency affect critical evaluation? Paper presented at $35^{\text {th }}$ Annual Conference of the Cognitive Science Society, Berlin, 2013. Retrieved from https://mindmodeling.org/cogsci2013/papers/0531/paper0531.pdf

Manalo, E., \& Uesaka, Y. (2012). Elucidating the mechanism of spontaneous diagram use in explanations: How cognitive processing of text and diagrammatic representations is influenced by individual and task-related factors. Lecture Notes in Artificial Intelligence, 7352, 3550. https://doi.org/10.1007/978-3-642-31223-6_9

McBride, R., Xiang, P., Wittenburg, D., \& Shen, J. (2002). An analysis of preservice teachers' dispositions toward critical thinking: A cross-cultural perspective. Asia-Pacific Journal of Teacher Education, 30(2), 131-140. https://doi.org/10.1080/13598660220135649

Moore, T. (2011). Critical thinking and language: The challenge of generic skills and disciplinary discourse. London: Bloomsbury. https://doi.org/10.5040/9781474211819

Mulvey, B. (2016). Writing instruction: What is being taught in Japanese high schools, why, and why it matters. The Language Teacher, 40(3), 3-8.

Myles, J. (2002). Second language writing and research: The writing process and error analysis in student texts. TESL-EL Journal, 6(2), 23-33.

Nickerson, R., Perkins, D., \& Smith, E. (1985). Teaching thinking. Hillsdale, NJ: Erlbaum Associates.

Nisbett, R., Peng, K., Choi, I., \& Norenzayan, A. (2001). Culture and systems of thought: Holistic versus analytic cognition. Psychological Review, 108(2), 291-310. https://doi.org/10.1037//0033295x.108.2.291

OECD (2009). Education at a glance 2009: OECD indicators. Retrieved from http://www.oecd.org/education/skills-beyond-school/43636332.pdf

OECD (2014). PISA 2012 results: Creative problem solving (Vol. 5). Students'skills in tackling real-life problems. OECD Publishing. http://dx.doi.org/10.1787/9789264208070-en. Retrieved from https://www.oecd.org/pisa/keyfindings/PISA-2012-results-volume-V.pdf

Journal of Contemporary Issues in Education, 2017, 12(2), pp. 18-33.

ISSN 1718-4770 @ 2017 University of Alberta/Centre for Global Citizenship Education and Research http://ejournals.library.ualberta.ca/index.php/JCIE 
O’Sullivan, M., \& Guo, L. (2010). Critical thinking and Chinese international students: An East-West dialogue. Journal of Contemporary Issues in Education, 5(2), 53-73. https://doi.org/10.20355/c5nk5z

Paas, F., Renkl, A., \& Sweller, J. (2003). Cognitive load theory and instructional design: Recent developments. Educational Psychologist, 38, 63-71. https://doi.org/10.1207/s15326985ep3801_1

Palfreyman, D. (2005). Othering in an English language program. TESOL Quarterly, 39(2), 211233. https://doi.org/10.2307/3588309

Paton, M. (2005). Is critical analysis foreign to Chinese students? In E. Manalo, \& G. Wong-Toi (Eds.), Communication skills in university education: The international dimension (pp. 1-11). Auckland, New Zealand: Pearson Education New Zealand.

Paton, M. (2011). Asian students, critical thinking and English as an academic lingua franca. Analytic Teaching and Philosophical Praxis, 32(1), 27-39.

Paul, R., \& Nosich, G. (1991). A proposal for the national assessment of higher-order thinking. Paper commissioned by the U.S. Department of Education Office of Educational Research and Improvement National Center for Education Statistics. Retrieved from http://www.criticalthinking.org/pages/a-model-for-the-national-assessment-of-higher-orderthinking/591

Perry, W. (1988). Different worlds in the same classroom. In P. Ramsden (Ed.), Improving learning: New perspectives (pp. 145-161). London: Kogan Page.

Scott, J., \& Markert, R. (1994). Relationship between critical thinking skills and success in pre-clinical courses. Academic Medicine, 69, 920-924. https://doi.org/10.1097/00001888-199411000-00015

Shaheen, N. (2016). International students' critical thinking-related problem areas: UK university teachers' perspectives. Journal of Research in International Education, 15(1), 1831. https://doi.org/10.1177/1475240916635895

Siller, T. (2001). Sustainability and critical thinking in civil engineering curriculum. Journal of Professional Issues in Engineering Education and Practice, 127(3), 104-108. https://doi.org/10.1061/(asce)1052-3928(2001)127:3(104)

Stigler, J., Gonzales, P., Kwanaka, T., Knoll, S., \& Serrano, A. (1999). The TIMSS videotape study: Methods and findings from an exploratory research project on eighth grade mathematics instruction in Germany, Japan, and the United States. Washington, DC, National Center for Education Statistics (NCES), 99-130. Retrieved from https://nces.ed.gov/pubs99/1999074.pdf

Swain, H. (2014). Why aren't Chinese students at UK universities getting top degrees? The Guardian, 15 April. Retrieved from https://www.theguardian.com/education/2014/apr/15/chinese-students-inuk-poor-results

Takano, Y., \& Noda, A. (1993). A temporary decline of thinking ability during foreign language processing. Journal of Cross-Cultural Psychology, 24(4), 445-462. https://doi.org/10.1177/0022022193244005

Taube, K. (1997). Critical thinking ability and disposition as factors of performance on a written critical thinking test. The Journal of General Education, 46, 129-164.

Thayer-Bacon, B. (1993). Caring and its relationship to critical thinking. Educational Theory, 43(3), 323340. https://doi.org/10.1111/j.1741-5446.1993.00323.x 
Tian, J. \& Low, G. (2011). Critical thinking and Chinese university students: A review of the evidence. Language, Culture and Communication, 24(1), 61-76. https://doi.org/10.1080/07908318.2010.546400

Tiwary, A., Avery, A., \& Lai, P. (2003). Critical thinking disposition of Hong Kong Chinese and Australian nursing students. Journal of Advanced Nursing, 44(3), 298-307. https://doi.org/10.1046/j.1365-2648.2003.02805.x

Tweed, R., \& Lehman, D. (2002). Learning considered within a cultural context: Confucian and Socratic approaches. American Psychologist, 57(2), 89-99. https://doi.org/10.1037//0003-066x.57.2.89

Vasagar, J. (2014, May 20). Countries that excel at problem-solving encourage critical thinking. Financial Times. Retrieved from https://www.ft.com/content/e512db9c-c643-11e3-ba0e00144 feabdc0

Ward, C., \& Masgoret, A-M. (2004). The experience of international students in New Zealand: Report on the results of the national survey. Prepared for the Ministry of Education by the Centre for Applied Cross-Cultural Research and School of Psychology, Victoria University of Wellington, Wellington. Retrieved from http://www.educationcounts.govt.nz/publications/international/14700

Watkins, D. A., \& Biggs, J. B. (2001). The paradox of the Chinese learner and beyond. In D. A. Watkins \& J. B. Biggs (Eds.), The Chinese learner: Cultural, psychological and contextual influences (pp. 3-23). Hong Kong: Comparative Education Research Centre, The University of Hong Kong.

Watson, T. (2000). Review: David Grant, Tom Keenoy and Cliff Oswick (Eds.), Discourse and organization. (Sage, 1998). Human Relations, 53(4), 559-573. https://doi.org/10.4135/9781446280270 